\title{
Long-term effects of fire and harvest on carbon stocks of boreal forests in northeastern China
}

\author{
Chao Huang ${ }^{1,2} \cdot$ Hong S. He ${ }^{3,4} \cdot$ Yu Liang ${ }^{1} \cdot$ Zhiwei Wu $^{1} \cdot$ Todd J. Hawbaker $^{5} \cdot$ Peng Gong ${ }^{6} \cdot$ Zhiliang Zhu $^{7}$
}

Received: 12 March 2017 / Accepted: 28 March 2018 / Published online: 6 July 2018

(C) INRA and Springer-Verlag France SAS, part of Springer Nature 2018

\begin{abstract}
- Key message Fire, harvest, and their spatial interactions are likely to affect boreal forest carbon stocks. Repeated disturbances associated with short fire return intervals and harvest rotations resulted in landscapes with a higher proportion of young stands that store less carbon than mature stands.

- Context Boreal forests represent about one third of forest area and one third of forest carbon stocks on the Earth. Carbon stocks of boreal forests are sensitive to climate change, natural disturbances, and human activities.

- Aims The objectives of this study were to evaluate the effects of fire, harvest, and their spatial interactions on boreal forest carbon stocks of northeastern China.

- Methods We used a coupled forest landscape model (LANDIS PRO) and a forest ecosystem model (LINKAGES) framework to simulate the landscape-level effects of fire, harvest, and their spatial interactions over 150 years.

- Results Our simulation suggested that aboveground carbon and soil organic carbon are significantly reduced by fire and harvest over the whole simulation period. The long-term effects of fire and harvest on carbon stocks were greater than the short-term effects. The combined effects of fire and harvest on carbon stocks are less than the sum of the separate effects of fire and harvest. The response of carbon stocks was impacted by the spatial variability of fire and harvest regimes.

- Conclusion These results emphasize that the spatial interactions of fire and harvest play an important role in regulating boreal forest carbon stocks.
\end{abstract}

Keywords Fire $\cdot$ Harvest $\cdot$ Carbon stocks $\cdot$ LANDIS PRO $\cdot$ LINKAGES $\cdot$ Model coupling

\begin{tabular}{l}
\hline Handling Editor: Erwin Dreyer \\
\hline Contribution of the co-authors Designed figures and tables in the \\
manuscript: Chao Huang, Hong S. He, Zhiwei Wu, and Yu Liang. \\
Conceived and designed the experiments: Chao Huang, Hong S. He, Yu \\
Liang, and Zhiwei Wu. Analyzed the data: Chao Huang, Yu Liang, Hong \\
S. He, and Todd J. Hawbaker. Wrote and revise the paper: Chao Huang, \\
Hong S. He, Yu Liang, Todd J. Hawbaker, Peng Gong, and Zhiliang Zhu.
\end{tabular}

Electronic supplementary material The online version of this article (https://doi.org/10.1007/s13595-018-0722-x) contains supplementary material, which is available to authorized users.

Hong S. He

heh@missouri.edu

Yu Liang

liangyu@iae.ac.cn

1 CAS Key Laboratory of Forest Ecology and Management, Institute of Applied Ecology, Chinese Academy of Sciences, No. 72, Wenhua Road, Shenhe District, Shenyang, Liaoning Province 110016, China

2 University of Chinese Academy of Sciences, Beijing 100049, China
3 School of Natural Resources, University of Missouri, 203 ABNR Building, Columbia, MO 65211, USA

4 School of Geographical Sciences, Northeast Normal University, Changchun 130024, China

5 U.S. Geological Survey, Geosciences and Environmental Change Science Center, Denver, CO 80225, USA

6 Ministry of Education Key Laboratory for Earth System Modeling, Center for Earth System Science, Tsinghua University, Beijing 100084, China

7 U.S. Geological Survey, Reston, VA 20192, USA 


\section{Introduction}

Boreal forests are an important component of the global carbon cycle (Lutz et al. 2013). They store $52.7 \pm 1.7$ Pg carbon in aboveground biomass and 170.5 \pm 3.8 Pg carbon in soil (Pan et al. 2011). The carbon stocks of boreal forests are strongly affected by fire and harvest (Barker et al. 2014). Fire and harvest alter forest productivity, release carbon directly into the atmosphere, and transfer carbon from live biomass into detritus, soils, and forest products (Bhatti et al. 2002; Kasischke et al. 2013). The carbon balance of boreal forests depends on the frequency and intensity of these disturbances (Chen et al. 2003; Clarke et al. 2015). For example, boreal forests in central and eastern Canada were carbon sources $\left(29 \pm 21 \mathrm{~g} \mathrm{~m}^{-2} \mathrm{C}\right.$ year) between 1990 and 1998 due to high-intensity fire, harvest, and insect outbreaks (Chen et al. 2003). Furthermore, climate change may increase the frequency and intensity of fire and insect disturbances, which will further exacerbate the loss of carbon from boreal forests (O'Donnell et al. 2011). Therefore, evaluating and distinguishing the effects of fire and harvest on boreal forest carbon stocks is of great importance for predicting the response of boreal forest carbon dynamics to climate change.

Boreal forests in the Great Xing' an Mountains cover $8.46 \times$ $10^{5} \mathrm{~km}^{2}$, store about $350 \mathrm{Tg}$ aboveground carbon, and play an important role in maintaining China's carbon balance (Fu et al. 2013). However, boreal forests in this region are facing pressures from repeated fires and timber harvesting activities. A total of 1614 fires burned $3.52 \times 10^{6}$ ha of boreal forests and released $293 \mathrm{Tg}$ carbon into the atmosphere during the 46-year time period from 1965 to 2010 in the Great Xing'an Mountains (Hu et al. 2012). Meanwhile, $3.38 \times 10^{6}$ ha of boreal forests has been harvested since the 1960s in this area (Zhang et al. 2009). Timber harvesting in this region is primarily clear-cutting, and these harvest activities have greatly altered forest composition, ecosystem processes, and landscape pattern. Furthermore, postfire salvage logging is a common forest management practice in the Great Xing' an Mountains (Chen et al. 2014), with the potential to alter forest regeneration and carbon stocks (Serrano-Ortiz et al. 2011). In order to maintain the productivity and ecological functions of China's boreal forests, it is essential to assess the long-term effects of repeated fire and harvest and their spatial interactions on carbon stocks.

Field studies have investigated the effects of fire and harvest in boreal forests on aboveground biomass (Wirth et al. 1999), soil organic carbon (Hazlett et al. 2007), and forest floor carbon (Boby et al. 2010; Shrestha and Chen 2010). These studies demonstrated that the effects of fire and harvest on boreal forest carbon stocks are a function of the balance between carbon loss from those disturbances and carbon gain from vegetation recovery. Normally, vegetation recovery after disturbance will transition forest stands from carbon sources to carbon sinks, and with sufficient time, the forest will sequester all the carbon lost from disturbances (Kashian et al. 2006). This implies that the long-term effects of fire and harvest on forest ecosystem carbon stocks are smaller than their short-term effects. However, most field studies were carried out using a space-for-time substitution within a relatively short time span (within a few decades) that was limited in capturing the inherently variable and stochastic nature of disturbances and vegetation recovery over long time periods (Piirainen et al. 2015). Although the space-for-time substitution approach can overcome limitations of short-duration field studies, they may fail to capture longer-term ecological processes of postdisturbance recovery (Gough et al. 2007). In addition, because climate change is likely to alter the frequency and severity of fire and species composition in boreal forests, the pathway of forest recovery and carbon stocks may also be affected (Anderson-Teixeira et al. 2013; Kasischke and Stocks 2012).

Ecological models are effective tools for studying the effects of repeated fire and harvest on forest carbon dynamics over long terms (Chertov et al. 2009). They have been used to investigate the effects of repeated fire and harvest on boreal forest carbon stocks in North America (Goetz et al. 2012; Govind et al. 2011), Europe (Moroni et al. 2010; Shanin et al. 2011), and China (Jiang et al. 2002; Luo et al. 2014). Additionally, ecological models can evaluate the uncertainties in how fire and harvest affect boreal forest carbon stocks by running replicate simulations (Kurz et al. 2008). Uncertainties in projections because of the stochastic nature of disturbances can be assessed by running multiple simulation scenarios. Moreover, separating the effects of fire and harvest has practical value for forest management policy-making that aims to minimize carbon loss from natural disturbances and human activities. However, few model-based studies have quantified the relative importance of periodic disturbances on boreal forest carbon stocks (Gustafson et al. 2010; Li et al. 2013).

The objective of this study was to quantify the long-term effects and relative importance of fire and harvest on carbon stocks of boreal forests in the Great Xing'an Mountains northeastern China. To do this, we used a coupled forest ecosystem and landscape model framework to predict aboveground carbon and soil organic carbon stocks at the landscape level. Specifically, we (1) examined the dynamics of aboveground carbon and soil organic carbon, as they changed in response to repeated fire and harvest; (2) quantified the relative importance of fire and harvest on boreal forest carbon stocks; and (3) assessed the effects of the spatial patterns of fire and harvest and their interactions on carbon stocks over 150 years.

\section{Methods}

\subsection{Study area}

Our study area included the Huzhong Natural Reserve (166,906 ha) and the Huzhong Forestry Bureau (770,338 ha), which are located in the northern side of the 
Great Xing'an Mountains (Fig. 1). The elevation ranges from $406 \mathrm{~m}$ in the northeast to $1514 \mathrm{~m}$ in the southwest. The climate is cool continental climate, with annual mean temperature of $-4.7^{\circ} \mathrm{C}$ and annual precipitation of about $497 \mathrm{~mm}$.

Our study area is classified into 26 ecoregions based on topography, forest types, and soil types (Fig. 1, Table S1). The terrace ecoregions (ecoregions $1-8$ ) contain $7 \%$ of the forests in our study area and are dominated by dahurian larch (Larix gmelini (Rupr. Kuzen)), white birch (Betula platyphylla Suk), poplar (Populus suaveolens Fisch), and willow (Chosenia arbutifolia (Pall.) A. Skv). Soils are sandy loam textured and poorly drained and have relatively low cation exchange capacity. Additionally, the Huma River and majority of the roads in the study area are located in the terrace ecoregions.

The south-slope ecoregions (ecoregions 9-16) include $36 \%$ of the forests in this region and are dominated by dahurian larch, white birch, aspen (Populus davidiana Dole) and Scots pine (Pinus sylvestris var. mongolica Litvinov). Many tree and understory species in the south-slope ecoregions are highly adapted to fire and readily resprout after crown fire. Soils are medium loam textured and well drained.

The north-slope ecoregions (ecoregions 17-21) account for $40 \%$ of forests in our study area and are dominated by dahurian larch, white birch, and Korean spruce (Picea koriensis Nakai). Vegetation regeneration after fire and harvest in the north-slope ecoregions was slower than that in the south-slope ecoregions (Cai et al. 2012). Soils are light clay textured and moderately drained and have a thick layer of humus.

The ridge-top ecoregions (ecoregions 22-26) are located in the south and southwest part of our study area, representing $17 \%$ forests in the Huzhong Natural Reserve and the Huzhong Forestry Bureau. Dwarf pine (Pinus pumila (Pall.) Regel) is a dominant evergreen shrub in the ridge-top ecoregions. Soils are medium loam textured, acidic, and moderately drained, and the Podzolic horizon was $5-10 \mathrm{~cm}$ thick.

More than $40 \%$ of forestland in Huzhong Forestry Bureau has been harvested since the 1970s. Timber harvesting has significantly altered stand age and affects tree species composition. Surface fire is the dominant fire type across most of the study area, except for occasional crown fire in high elevation areas in the Huzhong Natural Reserve. Lightning accounts for $48 \%$ of ignitions in our study area, over $75 \%$ of which occur in summer. In the Huzhong Forestry Bureau and Huzhong Natural Reserve, human- and lightning-caused fires burned 352,889 ha forest from 1967 to 2005 (Liu et al. 2012).

Fire and harvest regulate forest structure and determine boreal forest succession trajectories. In the Great Xing'an Mountains, pioneer species (white birch and aspen) establish quickly after crown fire or high-intensity harvest. The shade-tolerant species (larch and Scots pine) then regenerate and coexist with pioneer species over the next 50-100 years. As forest succession continues, the short-lived pioneer species (120-150 years) gradually die and give way to longer-lived shade-tolerant species (250-300 years). Finally, boreal forests

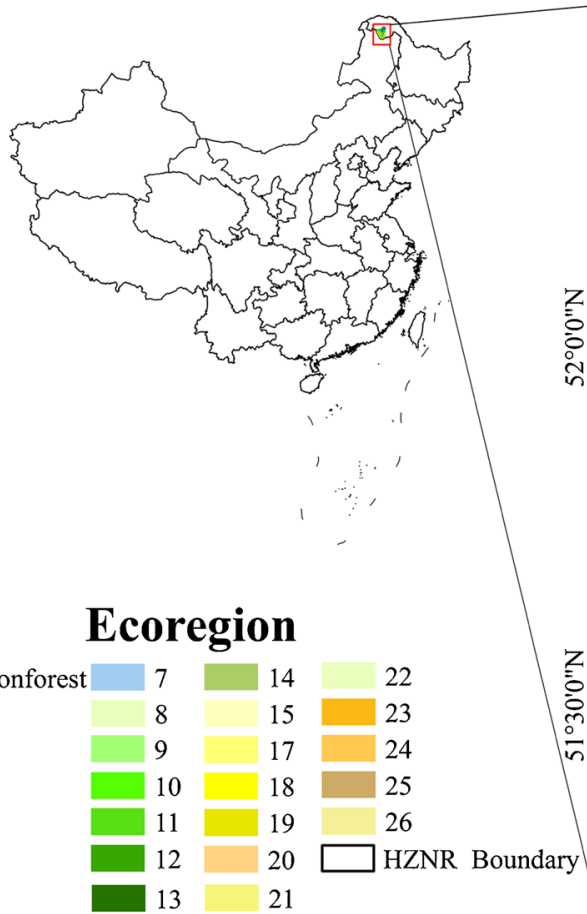

$123^{\circ} 0^{\prime} 0^{\prime \prime} \mathrm{E}$

$123^{\circ} 30^{\prime} 0^{\prime \prime} \mathrm{E}$

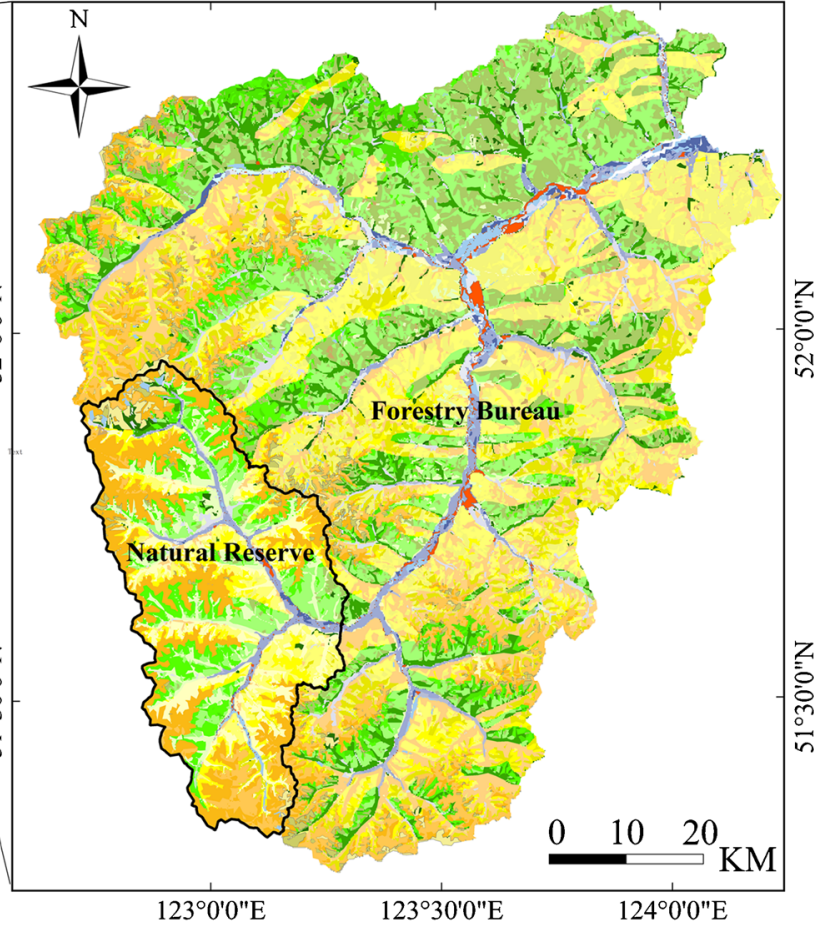

Fig. 1 The geographic location of our study area and 26 ecoregions. Nonforested areas are not simulated in this study. HZNR: Huzhong Natural Reserve 
will succeed to a climax community characteristic of coniferous larch forests in this region. Over the long term, fire and harvest resulted in forests dominated by dahurian larch, Scots pine, and white birch in the Great Xing'an Mountains. The stand age structure of these forests is affected primarily by fire and harvest. Mean stand age in our study area is 60 years old.

\subsection{The coupled modeling framework}

In this study, we used LANDIS PRO to assess the effects of fire and harvest on stand structure and aboveground carbon because it can simulate forest succession, seed dispersal, fire, and harvest over long time periods (Wang et al. 2014a). The LANDIS PRO model tracks the number and density of trees by species age cohort for each ecoregion, which makes it possible to estimate aboveground carbon using diameter at breast height (DBH) and stand density. However, LANDIS PRO cannot simulate soil carbon and nitrogen cycling because it lacks a biogeochemistry module. The LINKAGES model incorporates tree physiological processes, demographic processes, microbial processes, and hydrologic processes to simulates soil organic carbon and nitrogen dynamics (Post and Pastor 1996). LINKAGES was selected for this study because it can simulate soil organic carbon stocks under fire and harvest by coupling with the LANDIS PRO model (Huang et al. 2017). Specifically, we apply LANDIS PRO to simulate the dynamics of stand structure under succession, fire, harvest, and fire-harvest scenarios. Then, we use outputs of LANDIS PRO (number of trees, age, and DBH by each ecoregion) as stand parameters in LINKAGES, which predicts soil organic carbon at the ecoregion level (Fig. 2).

\subsubsection{LANDIS PRO model and parameterization}

LANDIS PRO is a forest landscape model that simulates forest succession under natural (e.g., fire, wind, insect, and disease outbreaks) and anthropogenic (e.g., harvest and fuel management) disturbances (Wang et al. 2016). The LANDIS PRO model tracks the number and density of trees by each species age cohort at the pixel level in addition to simulating growth, mortality, self-thinning, and species competition. The competition intensity is quantified as growing space occupied (GSO), which is estimated by Reineke's stand density index and pixel size (Wang et al. 2014a). These attributes can be used to calculate basal area or stocking percentage from tree volume and the number of trees. In LANDIS PRO, model parameters are compatible with commonly measured forest inventory and analysis data for easy parameterization, calibration, and validation (Wang et al. 2014b).

The fire module simulates fire occurrence, fire spread, and fire effects based on an ignition probability distribution, mean return interval, and mean size. Temporal patterns of fire regimes are simulated by a hierarchical fire frequency model, which divides fire occurrence into fire ignition and fire initiation (Yang et al. 2004). For each fire initiation, LANDIS PRO uses two percolation algorithms to estimate fire spread across the landscape from ignition points (Yang et al. 2008). The fire effect module determines which species' age cohorts are killed in a burned pixel (He and Mladenoff 1999). Fire effects are quantified as fire intensity that is determined by the quantity and quality of fuel in a pixel.

In the harvest module of LANDIS PRO, timber harvesting is simulated based on management area and stand maps. Management areas provide boundaries to constrain specific harvest events. Each management area is divided into stands that are the smallest contiguous units for harvesting operations (Fraser et al. 2013). In LANDIS PRO, trees harvested in a given stand are determined by stand age, basal area, stand stocking percent, and species composition.

Inputs for LANDIS PRO included raster maps (150 m resolution for this study) of ecoregion, species composition, species life history attributes, species establishment probability (SEP), and maximum growing space by each ecoregion. The species composition map was derived from China national forest inventory data and a forest type map that consists of the number of trees in each species age cohort. The forest type map was a GIS layer comprising boundaries of 46,862 stands that included forest composition information within each stand. China national forest inventory data, obtained from the Huzhong Forestry Bureau, contained numbers of trees by age class and DBH by species. The forest inventory plots were evenly distributed across the study area. In this study, we integrated the forest type map (polygon) and China national forest inventory data (point) to derive numbers of trees by age class for each species in the initial forest composition map. Species life history attributes (Table 1) were obtained from the Scientific Database of China Plant Species (http://db.kib.ac. cn) and previous studies ( $\mathrm{Li}$ et al. 2013; Luo et al. 2015). Species establishment probability (SEP) was estimated from a previous study in this region (Luo et al. 2015).

Fire return interval, mean fire size, and fire ignition probability were estimated based on a database of historical fire records (1967-2005). In this study, the ecoregion map is used as fire regime input map to reflect the geographic differences in fire regimes. Fire return interval, mean fire size, standard deviation of fire size, and fire ignition probability of each ecoregion are provided in Table S2. According to the forestry management plan of the Huzhong Forest Bureau, our study area was divided into three management areas: forbidden harvest areas, restricted harvest areas, and commercial harvest areas (Chen et al. 2015). Forbidden harvest areas cover 56\% of the forested areas in our study area and include the Huzhong National Natural Reserve and other conservation areas. In the restricted harvest areas and commercial harvest areas, larch, birch, and aspen are allowed to be harvested, whereas harvest of Scots pine, spruce, poplar, willow, and 
Fig. 2 The framework for coupling LANDIS PRO and LINKAGES models to predict aboveground carbon and soil organic carbon

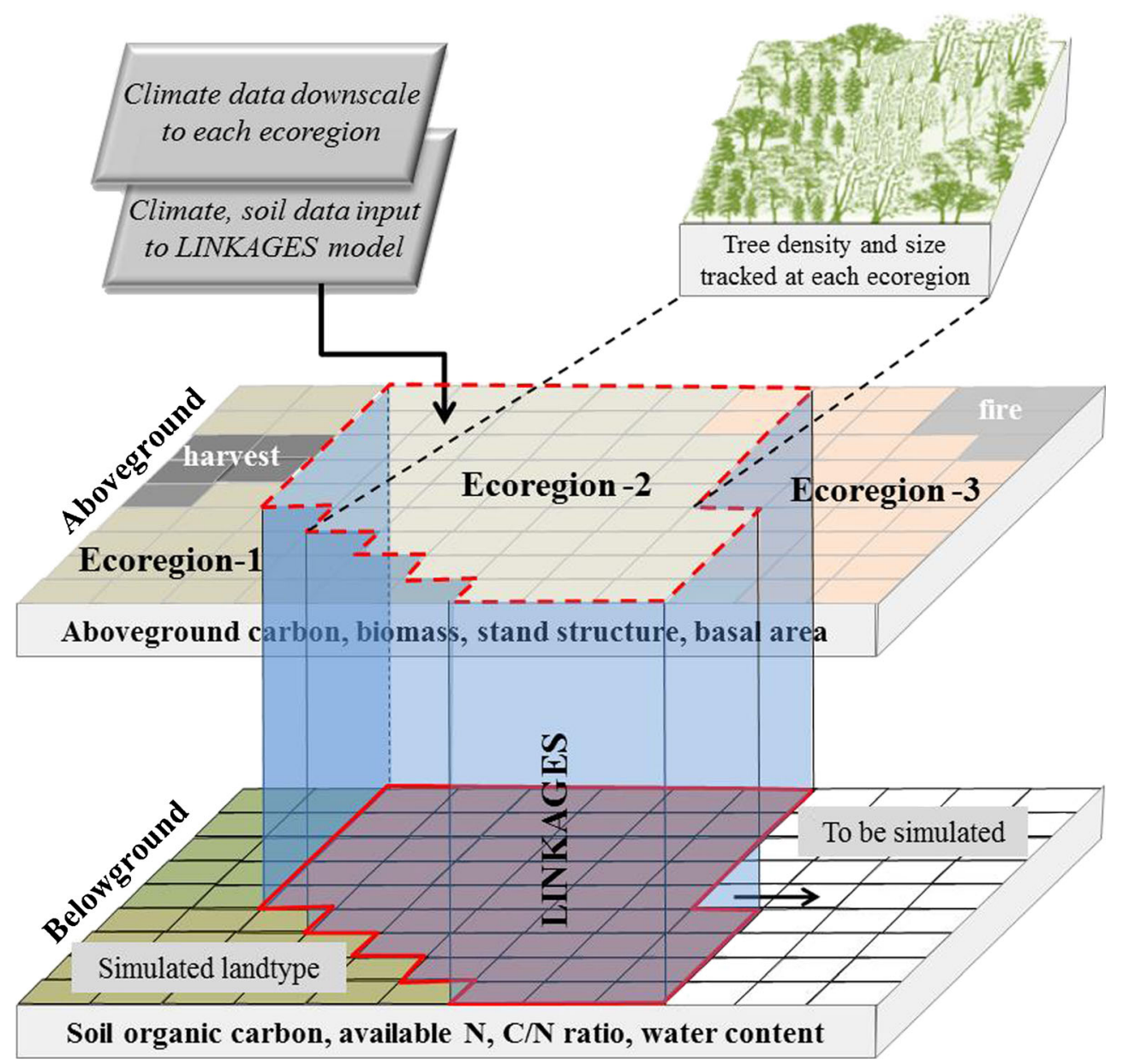

dwarf pine was not allowed. The main harvest method was stem-only clear-cutting (Table 2). The minimum stand age to harvest was 40 years. Three percent of the stands were harvested in the restricted harvest areas every 10 years $(350$ years rotation) and 5\% were harvested in the commercial harvest areas every 10 years (200 years rotation). The minimum stand age to harvest was 40 years. When a harvest event was triggered within a management area, stands were chosen using a stocking level ranking algorithm (Fraser et al. 2013). Adjacent stands are not harvested for at least 10 years (Luo et al. 2014). In this study, we assumed that only legal harvesting was carried out, and the current fire and harvesting parameters did not vary during the whole simulation period (Table 2).

\subsubsection{LINKAGES V2.2 model and parameterization}

LINKAGES v2.2 is a forest ecosystem model that is designed to simulate the dynamics of soil organic carbon and nitrogen evolved from LINKAGES1.0 (Wullschleger et al. 2003). LINKAGES v2.2 includes daily weather data, litter decomposition, mineralization, soil moisture, evaporation, tree species birth, growth, and mortality subroutines. These subroutines allow soil nutrient cycles to interact with species composition
(Dijak et al. 2016). In LINKAGES v2.2, species composition affects the dynamics of soil organic carbon because species differ widely in how their litter affects soil nitrogen availability (Post and Pastor 1996). The main parameters of LINKAGES v2.2 include daily maximum and minimum temperature, daily precipitation, daily mean incoming solar radiation, daily mean wind speed, growing season degree-days, number of trees, diameter at breast height, age, number of soil layers, thickness of soil layer, soil layer field capacity, soil layer wilting point, soil organic matter, and soil nitrogen content.

Daily weather data for LINKAGES v2.2 were derived from the China national daily meteorological monitoring dataset (1975-2000; http://data.cma.gov.cn). We obtained soil parameters (thickness of soil layer, organic matter, nitrogen, rock fragment, clay and sand content) from a national soil database (http://www.soil.csdb.cn). Soil water-holding capacity and wilting point were estimated by rock fragment and clay and sand content (Table S3). The species parameters (Table 3) were derived from a previous study in northeastern China ( $\mathrm{He}$ et al. 2005). Within each ecoregion, the number of trees, age, and DBH were obtained from the output of the LANDIS PRO model. 
Table 1 Major species life history attributes for the LANDIS PRO model

\begin{tabular}{|c|c|c|c|c|c|c|c|c|c|c|c|c|}
\hline Species & $\mathrm{LONG}^{\mathrm{a}}$ & $\mathrm{MTR}^{\mathrm{b}}$ & $\mathrm{SHD}^{\mathrm{c}}$ & FIRE $^{\mathrm{d}}$ & $\mathrm{EFFD}^{\mathrm{e}}$ & $\operatorname{MAXD}^{\mathrm{f}}$ & VGP $^{g}$ & MAXDBH $^{\mathrm{h}}$ & MAXSDI $^{\mathrm{i}}$ & $\mathrm{NPGS}^{\mathrm{j}}$ & $\mathrm{CARBONCO}^{\mathrm{k}}$ & $\mathrm{SEP}^{1}$ \\
\hline Dahurian larch & 300 & 20 & 2 & 5 & 50 & 400 & 0 & 70 & 600 & 10 & 0.4234 & 0.288 \\
\hline White birch & 150 & 15 & 1 & 3 & -1 & 2400 & 1 & 30 & 690 & 30 & 0.421 & 0.153 \\
\hline Korean spruce & 300 & 30 & 4 & 1 & 100 & 300 & 0 & 60 & 520 & 10 & 0.48 & 0.06 \\
\hline Scots pine & 250 & 25 & 2 & 4 & 100 & 300 & 0 & 70 & 560 & 10 & 0.412 & 0.175 \\
\hline Aspen & 120 & 10 & 1 & 1 & -1 & 2400 & 1 & 50 & 680 & 30 & 0.3921 & 0.01 \\
\hline Poplar & 180 & 12 & 1 & 2 & -1 & -1 & 1 & 50 & 780 & 20 & 0.4144 & 0.013 \\
\hline Willow & 250 & 12 & 2 & 1 & -1 & -1 & 0.9 & 50 & 780 & 20 & 0.43 & 0.018 \\
\hline Dwarf pine & 250 & 15 & 3 & 3 & 90 & 100 & 0 & 20 & 340 & 5 & 0.51 & 0.225 \\
\hline
\end{tabular}

${ }^{\text {a }}$ LONG, longevity of the species (years)

${ }^{\mathrm{b}}$ MTR, maturity age of the species in year

${ }^{\mathrm{c}} \mathrm{SHD}$, shade tolerance $(1-5,1=$ least tolerant; 5 = most tolerant $)$

${ }^{\mathrm{d}}$ FIRE, fire tolerance $(1-5,1=$ least tolerant; 5 = most tolerant)

${ }^{\text {e }}$ EFFD, species effective seeding distance $(\mathrm{m}),-1$ represents unlimited effective seeding range

${ }^{\mathrm{f}}$ MAXD, species maximum seeding distance $(\mathrm{m}),-1$ represents unlimited effective seeding range

${ }^{\mathrm{g}}$ VGP, probability of vegetative propagation

${ }^{\mathrm{h}} \mathrm{MAXDBH}$, maximum diameter at breast height of species in centimeters

${ }^{\mathrm{i}} \mathrm{MAXSDI}$, maximum stand density (number of $25.5 \mathrm{~cm}$ trees per hectare)

${ }^{\mathrm{j}} \mathrm{NPGS}$, number of potential germination seeds

${ }^{\mathrm{k}}$ CARBONCO, carbon coefficient. This coefficient represents the amount of carbon in the wood of each species

${ }^{1} \mathrm{SEP}$, species establishment probability. The establishment of the potential sprouting seedlings is determined by this coefficient

\subsection{Simulation design and data analysis}

To assess the long-term effects of fire and harvest on boreal forest carbon stocks, we designed four simulation scenarios: (1) succession-only scenario (fire and harvest were not simulated), (2) fire scenario (wherein fire and succession were simulated with the current fire regimes), (3) harvest scenario (whereby harvest and succession were simulated, with harvest regime reflecting current harvest practices in the Huzhong Forestry Bureau), and (4) fire-harvest scenario (whereby fire, harvest, and succession were simulated to reflect current conditions). The four simulation scenarios were simulated from year 2000 to 2150 at 10 -year time steps with five replications to estimate uncertainties in the simulation results (Liang et al. 2012).

To quantify the effects of fire and harvest on carbon stocks, we compared the simulation results from the four simulation scenarios. In order to examine the temporal variation in fire and harvest effects, our simulation results were analyzed separately for the short term (0-20 years), medium term (3050 years), and long term (60-150 years). We used analysis of variance (ANOVA) to test the significance of the differentiation among fire and harvest and their combined effects over the short term, medium term, and long term. The Tukey's honest significant difference method was used for post hoc analyses $(p=0.05)$. To analyze the effects of fire and harvest on the spatial distribution of boreal forest carbon stocks, we compared the spatial changes of fire and harvest and their combined effects on carbon stocks at 50,100, and 150 years. Three typical ecoregions (ecoregion-1, ecoregion-10, and ecoregion-25) were used to analyze the spatial variability of fire and harvest effects.

The "relaimpo" package (Gromping 2006) in R statistical software was used to calculate the relative importance of fire and harvest on boreal forest carbon stocks. This package
Table 2 The main parameters of the harvest module

\begin{tabular}{|c|c|c|c|c|c|}
\hline \multirow[t]{2}{*}{ Species } & \multirow{2}{*}{$\begin{array}{l}\text { Age } \\
\text { (years) }\end{array}$} & \multirow{2}{*}{$\begin{array}{l}\text { Cutting } \\
\text { method }\end{array}$} & \multicolumn{2}{|c|}{ Proportion area of harvested (\%) } & \multirow{2}{*}{ Regeneration } \\
\hline & & & $\begin{array}{l}\text { Restricted harvest } \\
\text { areas }\end{array}$ & $\begin{array}{l}\text { Commercial harvest } \\
\text { areas }\end{array}$ & \\
\hline $\begin{array}{l}\text { Dahurian } \\
\text { larch }\end{array}$ & $120-300$ & Clear-cut & 3 & 5 & Natural \\
\hline White birch & $60-150$ & Clear-cut & 3 & 5 & Natural \\
\hline Aspen & $40-120$ & Clear-cut & 3 & 5 & Natural \\
\hline
\end{tabular}

The proportion of area harvested is a proportion of management area that will be harvested per decade 
Table 3 The major species parameters of the LINKAGES v2.2 model

\begin{tabular}{|c|c|c|c|c|c|c|c|c|c|c|c|}
\hline Species & DMAX $^{\mathrm{a}}$ & $\mathrm{DMIN}^{\mathrm{b}}$ & $\mathrm{B} 3^{\mathrm{c}}$ & $\mathrm{B} 2^{\mathrm{c}}$ & SWITCH $^{\mathrm{d}}$ & $\mathrm{D} 3^{\mathrm{e}}$ & FROST $^{f}$ & $\mathrm{FWT}^{\mathrm{g}}$ & $\mathrm{TL}^{\mathrm{h}}$ & $\mathrm{RTST}^{\mathrm{i}}$ & $\mathrm{FRT}^{\mathrm{j}}$ \\
\hline Dahurian larch & 1900 & 400 & 0.35 & 63.62 & FFFFT & 0.424 & -35 & 248 & 12 & 1 & 1 \\
\hline White birch & 3100 & 600 & 0.52 & 73.23 & FFFFT & 0.412 & -40 & 248 & 4 & 0.8 & 1 \\
\hline Korean spruce & 2500 & 600 & 0.38 & 68.07 & FTFFF & 0.11 & -35 & 440 & 11 & 1 & 3 \\
\hline Scots pine & 1900 & 700 & 0.37 & 59.08 & TTTFF & 0.6 & -30 & 440 & 12 & 1 & 3 \\
\hline Aspen & 3000 & 800 & 0.66 & 78.77 & TTFFT & 0.333 & -26 & 440 & 7 & 0.5 & 1 \\
\hline Poplar & 1600 & 600 & 0.35 & 63.62 & TTFFT & 0.1 & -35 & 440 & 7 & 0.5 & 1 \\
\hline Willow & 2400 & 600 & 0.29 & 57.26 & TTFFT & 0.08 & -35 & 248 & 7 & 0.5 & 1 \\
\hline Dwarf pine & 1400 & 300 & 1.16 & 46.30 & TTFFF & 0.2 & -40 & 248 & 12 & 1 & 3 \\
\hline
\end{tabular}

${ }^{a}$ DMAX, degree day maximum for each species (degree)

${ }^{\mathrm{b}} \mathrm{DMIN}$, degree day minimum for each species (degree)

${ }^{\mathrm{c}} \mathrm{B} 2$ and B3 are growth scaling parameters for each species

${ }^{\mathrm{d}}$ SWITCH, reproduction switches

${ }^{\mathrm{e}} \mathrm{D} 3$, drought tolerance (fraction of growing season, \%)

${ }^{\mathrm{f}}$ FROST, minimum January temperature tolerated (degree)

${ }^{\mathrm{g}}$ FWT, leaf weight per unit crown area $\left(100 \mathrm{~g} / \mathrm{m}^{2}\right)$

${ }^{\mathrm{h}} \mathrm{TL}$, leaf litter quality class (1-12 are the leaf litter; 13 is root litter; 14 and 15 are fresh wood from tress less than or greater than $10 \mathrm{~cm} ; 16$ is twig litter; 17 is well-decayed wood not contain humus)

${ }^{\mathrm{i}} \mathrm{RTST}$, root-shoot ratio for each species

${ }^{\mathrm{j}}$ FRT, foliage retention time (years)

implements the weighted averages with data-dependent weights method (pmvd) for assessing relative importance of predictor variables in multiple linear regressions. It also computes $R_{\text {pmvd }}^{2}$, or the average contribution of each variable to the overall $R^{2}$ across all possible orderings, and thus provides a unique decomposition of the explained variance when predictors are correlated (Belmaker and Jetz 2011). The relative importance of fire and harvest was normalized (divided by $R^{2}$ ) to sum to 1 (Carvalhais et al. 2014). With this method, we analyzed two response variables (aboveground carbon and soil organic carbon) at the short term, medium term, and long term. The R statistical software v3.2.2 (R Core Team 2015) was used in data analyses.

Data availability The data generated or analyzed during this study are included in this published article and its supplementary information files.

\section{Results}

\subsection{The effects and relative importance of fire and harvest and their combined effects on aboveground carbon}

Aboveground carbon increased with simulation time at the landscape level under the succession-only scenario, fire, harvest, and fire-harvest scenarios (Fig. 3). Compared to succession-only scenario, aboveground carbon was reduced by $2.3 \pm 0.6 \mathrm{t} / \mathrm{ha}$ in the fire scenario, $6.0 \pm 1.4 \mathrm{t} / \mathrm{ha}$ in the harvest scenario, and $8.0 \pm 1.9 \mathrm{t} / \mathrm{ha}$ in the fire-harvest scenario. The largest aboveground carbon reduction occurred in the fire-harvest scenario, accounting for $22 \%$ of the average value of the simulated aboveground carbon in the succession-only scenario. In the harvest scenario, aboveground carbon was 10 and $15 \%$ lower than that in the fire and succession-only scenarios, respectively. At the landscape level, the combined effects of fire and harvest on aboveground carbon were smaller than the sum of their effects in the fire scenario and the harvest scenario.

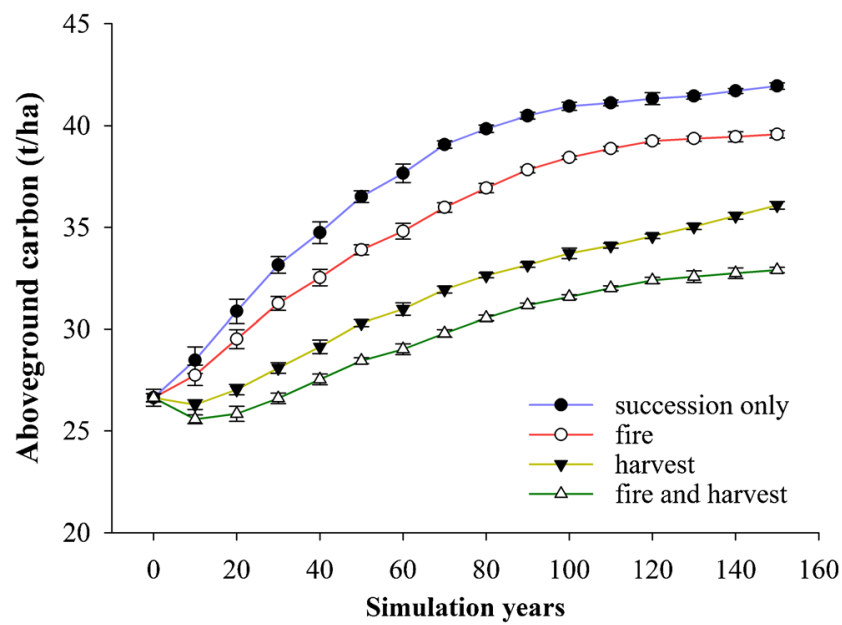

Fig. 3 Total landscape mean aboveground carbon for succession-only, fire, harvest, and fire-harvest scenarios over 150 years 
The effects of fire and harvest on aboveground carbon varied among the three time periods (Table 4). In the short term (years $0-20$ ), the effects of fire on aboveground carbon were significantly lower than those in the medium and long term $(p<0.05)$. The effects of fire and harvest on aboveground carbon did not vary significantly between the medium and long term $(p>0.05)$. At medium term, the effects of harvest on aboveground carbon were $5.7 \pm 0.4 \mathrm{t} / \mathrm{ha}$, which were significantly higher than in short term. The combined effect of fire and harvest on aboveground carbon differed significantly among the three time periods $(p<0.05)$.

The relative importance of fire on aboveground carbon was $30.9,26.8$, and $14.2 \%$ in the three time periods, respectively (Fig. $4)$. The relative importance of harvest on aboveground carbon was greater than fire $(69.1,73.2$, and $85.8 \%$ in the three time periods, respectively). The relative importance of harvest on aboveground carbon increased with simulation time; however, the relative importance of fire declined over 150 years.

\subsection{The effects and relative importance of fire and harvest and their combined effects on soil organic carbon}

At the landscape level, soil organic carbon increased with simulation year irrespective of fire and harvest (Fig. 5). Compared to the succession-only scenario, fire reduced soil organic carbon by $5.4 \pm 3.1 \mathrm{t} / \mathrm{ha}$, harvest by $5.8 \pm 3.3 \mathrm{t} / \mathrm{ha}$, and fire-harvest by $6.5 \pm 3.4$ tha over 150 years. The largest soil organic carbon reduction occurred in the fire-harvest scenario, accounting for $8 \%$ of the simulated value in the succession-only scenario. In the fire and harvest scenarios, soil organic carbon was 6 and $7 \%$ lower than that in the succession-only scenario. The combined effects of fire and harvest on soil organic carbon were less than the sum of the separate effects of fire and harvest.

The effects of fire and harvest on aboveground carbon were significantly different at three time periods (Table 5). In the short term, the effects of fire on soil organic carbon were $0.48 \pm 0.41 \mathrm{t} / \mathrm{ha}$, which were significant lower than those in the medium and long term $(p<0.05)$. Over the long term, the effects of harvest on soil organic carbon were $7.7 \pm 2.3 \mathrm{t} / \mathrm{ha}$, which were significantly higher than those in the short term and medium term. The combined effect of fire and harvest on soil organic carbon differed significantly among the three time periods $(p<0.05)$.

Table 4 Reductions in aboveground carbon after fire and harvest (unit: t/ha)

\begin{tabular}{llll}
\hline Period & Fire effects & Harvest effects & Combined effects \\
\hline Short term (0-20 years) & $0.9 \pm 0.4(3.0 \%) \mathrm{a}$ & $2.6 \pm 1.1(8.7 \%) \mathrm{a}$ & $3.4 \pm 1.4(10.5 \%) \mathrm{a}$ \\
Medium term (30-50 years) & $2.2 \pm 0.3(6.5 \%) \mathrm{b}$ & $5.7 \pm 0.4(16.4 \%) \mathrm{b}$ & $7.3 \pm 0.5(25.3 \%) \mathrm{b}$ \\
Long term (60-150 years) & $2.5 \pm 0.4(6.1 \%) \mathrm{b}$ & $6.8 \pm 0.5(16.7 \%) \mathrm{b}$ & $9.1 \pm 0.2(26.9 \%) \mathrm{c}$ \\
\hline
\end{tabular}

Note: "a," "b," and "c" indicate significant differences $(p<0.05)$ between time periods, testing using analysis of variance (ANOVA) and Tukey's honest significant difference method
The relative importance of harvest on soil organic carbon was greater than fire (Fig. 6). The relative importance of harvest on soil organic carbon was $86.4,76.1$, and $62.0 \%$ in the three time periods, respectively. Meanwhile, the relative importance of fire was $13.6,23.9$, and $37.0 \%$ in the short, medium, and long term. The relative importance of fire on soil carbon increased over time. In contrast, the relative importance of harvest on soil organic carbon decreased continuously over the 150-year simulations.

\subsection{The spatiotemporal pattern of fire and harvest and their combined effects on boreal forest carbon stocks}

In the three time periods, the spatial patterns of fire and harvest effects on boreal forest carbon stocks significantly differed among the fire, harvest, and fire-harvest scenarios (Fig. 7). After 150 years, the area affected by fire and harvest was $13 \%$ higher than it was after 50 years of simulation. The effects of fire on carbon stocks mostly occurred in the northwest (Huzhong Natural Reserve) and the ridge ecoregion over $800 \mathrm{~m}$ elevations. The main concentration of carbon stocks reduced by harvest occurred in commercial and restricted harvest areas, which included $45 \%$ of forest in our study area.

The effects of fire and harvest on boreal forest carbon stocks varied in different ecoregions (Fig. 8). In the terrace ecoregion (ecoregion-1), low fire frequency and relatively low harvest intensity led to less carbon stocks removed by these disturbances. In the south-slope ecoregion (ecoregion-10), relatively higher fire and harvest frequency tended to lower aboveground carbon and soil organic carbon over 150 years (Fig. 7). In the ridge top ecoregion (ecoregion-25), fire had greater effects on aboveground carbon and soil organic carbon than harvest, due to the frequency of fire being greater than the frequency of harvest in this area. These divergent responses were largely dependent on the intensity of fire and harvest among different ecoregions.

\section{Discussion}

In this study, we examined the effects of fire, harvest, and their spatial interactions on boreal forest carbon stocks of the Great Xing'an Mountains. Our simulation results showed that 


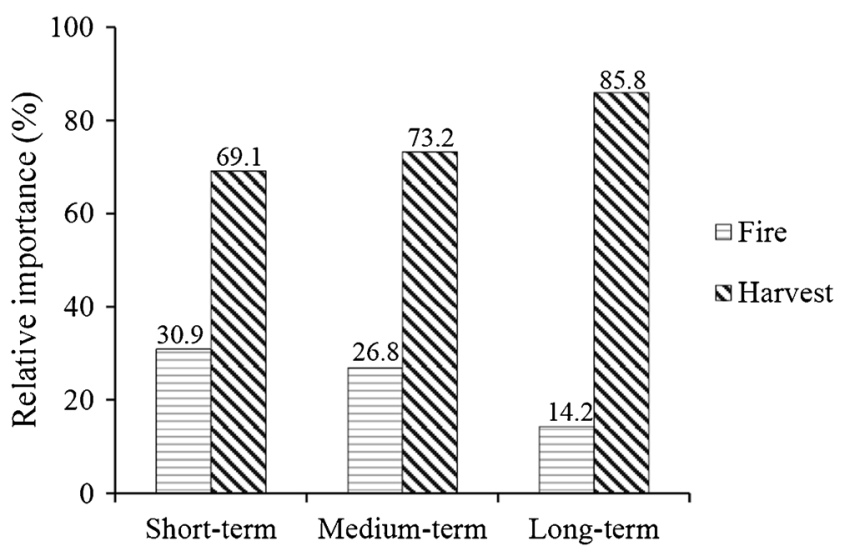

Fig. 4 Relative importance of fire and harvest on aboveground carbon ( $\mathrm{t} / \mathrm{ha}$ ) at three time periods (short term 0-20 years; medium term 3050 years; long term $60-150$ years)

recurrent fires, harvests, and their spatial interactions have strong effects on boreal forest carbon stocks in northeastern China. At the landscape level, the long-term effects of fire and harvest on carbon stocks were greater than the short-term effects. The extent of carbon loss by fire and harvest depended on the intensity of these disturbances. Harvest plays a more important role in affecting boreal forest carbon stocks than fire, which may be attributed to the high intensity of clear-cuts. The spatial distribution of boreal forest carbon stocks was affected by the spatial pattern of fire and harvest in different ecoregions.

Our simulation results showed that fire, harvest, and their spatial interactions decreased aboveground carbon and soil organic carbon over the short term. This result is generally consistent with previous studies (Kashian et al. 2006; Thornley and Cannell 2004) in boreal forests. However, the short-term effects of fire and harvest on boreal forest carbon stocks in our study are smaller than those in some field studies. For example, Hu et al. (2016) found that fire reduced aboveground carbon by $9.5-16.5 \mathrm{t} / \mathrm{ha}$ in the larix gmelinii-grass

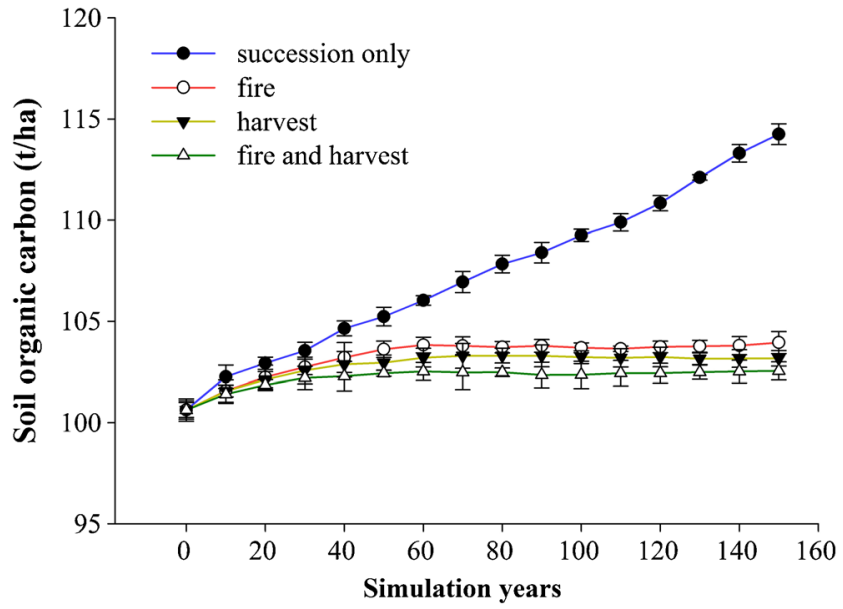

Fig. 5 Total landscape mean soil organic carbon for succession, fire, harvest, and fire-harvest scenarios over 150 years stands of the Great Xing'an Mountains during 1987-2014. The discrepancy in the extent of fire effects between our study and those of $\mathrm{Hu}$ et al. (2016) was likely due to the differences in estimation methods. In their study, the effects of fire and harvest on aboveground carbon were calculated as the difference in carbon between disturbed and undisturbed plots. Beyond the plot level, disturbances rarely entirely burn or harvest an entire landscape due to environmental heterogeneity, and thus, plot-level assessments tended to overestimate disturbance effects (Dean et al. 2004). This discrepancy suggests that accounting for disturbance intensity and extent as well as landscape configuration is important for regional-scale carbon stock assessments. Meanwhile, some field studies indicated that additional inputs of litter associated with fire and stem-only harvesting cause a short-term increase in soil carbon stocks (Johnson and Curtis 2001). However, most field studies were conducted within a relatively short period of time (e.g., $<20$ years) and, therefore, may not capture the long-term impacts of disturbances on soil organic carbon (Clarke et al. 2015). Since our simulation time step is 10 years, most such short-term spikes in postdisturbance soil organic matter were smoothed out.

Our results showed that the effects of fire, harvest, and their spatial interaction on boreal forest carbon stocks increased from the short to long term. Aboveground carbon was reduced by harvest $6.8 \pm 0.5 \mathrm{t} / \mathrm{ha}$ over the long term, which was about three times greater than the short-term effects. Our findings contradict some previous studies suggesting that forest recovery after fire and harvest can offset the effects of these disturbances on forest carbon stocks over the long term (Chen and Shrestha 2012; Nalder and Wein 1999). This is because fire and harvest usually occur in different stands at different times that alter the distribution of stand ages across a landscape. More frequent fire and harvest will promote a higher proportion of young stands in the landscape. Young stands in the landscape tend to store less carbon than old and mature stands, but have higher carbon sequestration rates (Alexandrov 2007; Kashian et al. 2006). In addition, many boreal forests experience repeated disturbances associated with relatively short fire return intervals and harvest rotations (Bergeron et al. 2001; Bose et al. 2013). Over the long term, repeated fire and harvest not only increase carbon losses from fire emissions and timber removals (Cheng et al. 2013) but also alter the carbon recovery trajectory of boreal forest ecosystems (Johnstone and Chapin 2006; Steenberg et al. 2012). Our findings reinforce the importance of long-term studies when assessing the effects of fire and harvest on boreal forest carbon stocks and demonstrate the utility of ecological simulation models for assessing long-term disturbance impacts.

The results from our study showed that harvest was more important than fire in affecting boreal forest carbon stocks over 150 years (Figs. 4 and 6). There are several reasons for such results. First, the percentage of area affected by timber 
Table 5 Reductions in soil organic carbon after fire and harvest (unit: $\mathrm{t} / \mathrm{ha}$ )

\begin{tabular}{llll}
\hline Period & Fire effects & Harvest effects & Combined effects \\
\hline Short term (0-20 years) & $0.4 \pm 0.2(0.3 \%) \mathrm{a}$ & $0.5 \pm 0.2(0.4 \%) \mathrm{a}$ & $0.6 \pm 0.3(0.5 \%) \mathrm{a}$ \\
Medium term (30-50 years) & $1.8 \pm 0.6(1.7 \%) \mathrm{b}$ & $2.0 \pm 0.9(1.9 \%) \mathrm{b}$ & $2.4 \pm 0.9(2.2 \%) \mathrm{b}$ \\
Long term (60-150 years) & $7.2 \pm 2.3(6.5 \%) \mathrm{c}$ & $7.7 \pm 2.3(7.0 \%) \mathrm{c}$ & $8.5 \pm 2.3(7.7 \%) \mathrm{c}$ \\
\hline
\end{tabular}

Note: "a," "b," and "c" indicate significant differences $(p<0.05)$ between time periods, testing using analysis of variance (ANOVA) and Tukey's honest significant difference method harvesting is much larger than that of fire (Fig. 7). Second, clear-cutting not only removes more aboveground biomass than fire but also markedly increases soil temperature, and this might lead to increased litter decomposition and hence increased carbon release from mineral soil by heterotrophic respiration (Zha et al. 2009). Third, the rate of tree regeneration after clear-cutting is slower than after fire (Cai et al. 2013; Xu et al. 2006), which may delay forest carbon recovery over the long term (Carlson et al. 2012). This implies that harvest is the primary disturbance controlling carbon stocks in boreal forests of the Great Xing'an Mountains.

Our simulation demonstrated that the effects of fire and harvest are less than the sum of carbon loss from the fire and harvest-only scenarios. This is because timber harvesting reduces fuel loads, thereby decreasing the risk of high-severity fire (Bury 2004). The forest gaps caused by high-intensity harvest have negative impacts on fire spread and tree damage (Kiefer et al. 2016). Our results suggest that harvest may come at the expense of less carbon on the landscape, but reduces the amount of carbon loss to high-severity fires. This implies that moderate timber harvesting may be a useful tool for limiting carbon loss from catastrophic fires in the fire-prone forests.

Meanwhile, our results showed that the effects of fire and harvest on carbon stocks varied among ecoregions due to differences in fire and harvest regimes. This is similar to a previous study that showed the divergent response of carbon dynamics among ecoregions and climate change scenarios was due to the spatial pattern of soils, tree species, and

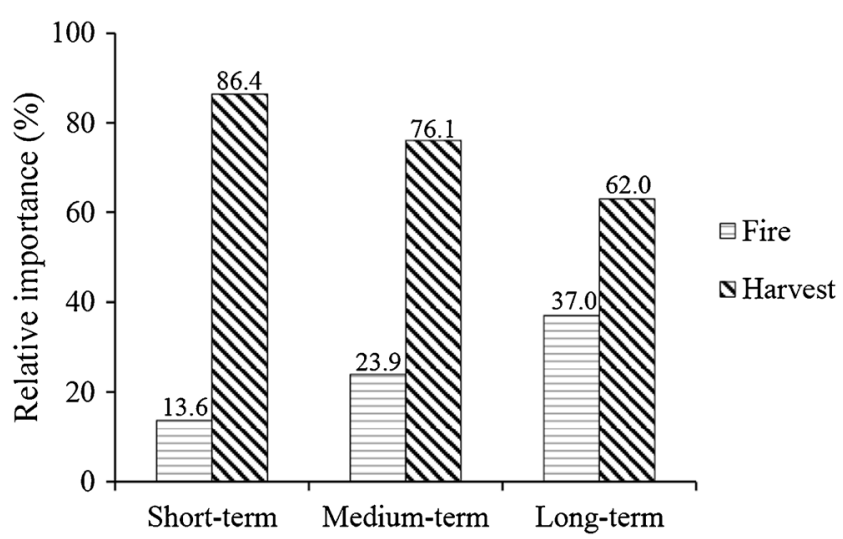

Fig. 6 Relative importance of fire and harvest on soil organic carbon at three time periods (short term $0-20$ years; medium term $30-50$ years; long term $60-150$ years) land-use histories (Scheller et al. 2012). In the terrace ecoregion (ecoregion-1), fire and harvest had smaller effects on boreal forest carbon stocks than they did in other ecoregions. The terrace ecoregion is located in a plain which is close to the Huma River, roads, and settlements, where fires were mostly of human origin and most fires were small in size due to suppression (Wu et al. 2015). In addition, most forests in the terrace ecoregion belonged to areas where timber harvesting was forbidden and consequently had limited effects, whereas fire had greater effects on carbon stocks than harvest in the ridge top ecoregion (ecoregion-25). Most of the forest in the ridge top ecoregion was over $800 \mathrm{~m}$ elevation. Fires in this ecoregion were primarily of lightning origin. Most of the fires were not suppressed because of the remoteness, and the fire sizes were large (Wu et al. 2014). The effects of harvest were smaller than fire in this ecoregion due to approximately $70 \%$ forest in the ridge-top ecoregion being in forbidden harvest areas. These results suggested that the spatial distribution of boreal forest carbon stocks is influenced by the spatial pattern of fire and harvest among different ecoregions.

Boreal forest carbon stocks are the results of the interactions between climate, stand age, species composition, soil nutrients, and disturbances. It is challenging to accurately predict boreal forest carbon stocks under different disturbance regimes over long time periods. Ecological models provide a unique scientific approach for long-term prediction of the effects of fire and harvest on forest carbon stocks. The simulation results of ecological models can illustrate general trends in forest carbon stocks and provide insight into how fire and harvest affect forest dynamics in the future (He et al. 2011, 2017; Shifley et al. 2006). However, validation of simulation results requires long-term spatial and temporal field data, which are not readily available. In this study, forest inventory data and mature forests in the Huzhong Natural Reserve were used to validate model performance. The results of the model validation showed that simulated values were comparable to observed values derived from the forest inventory data and Huzhong Natural Reserve (Huang et al. 2017).

Our study quantified the long-term effects of fire, harvest, and their spatial interactions on boreal forest carbon stocks based on a series of reasonable assumptions. First, this study is based on the assumption that fire regimes in our study area remained unchanged over the simulation period. Over the long term, the frequency and intensity of fire is closely related 
Fig. 7 Spatial pattern of the effects of fire and harvest and their spatial interaction on aboveground carbon and soil organic carbon after 50,100 , and 150 years of simulation
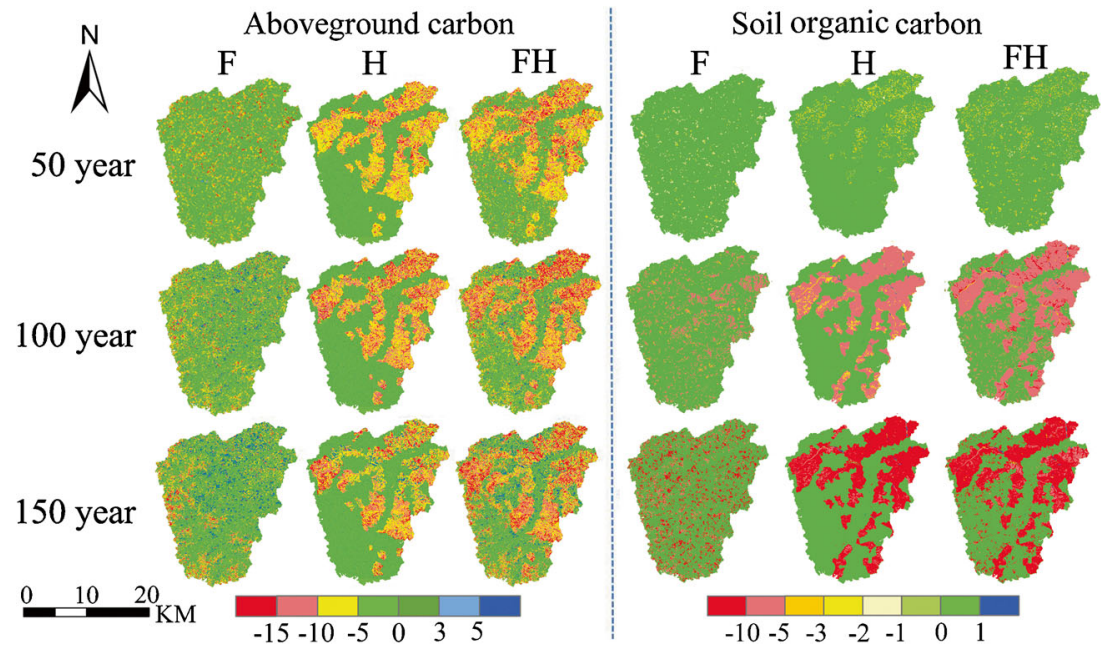

to climate variables, that may impact forest carbon dynamics (Running 2008). As the frequency and intensity of fire is expected to increase in the future due to climate change (Flannigan et al. 2005), fire will further reduce the carbon stocks in boreal forests of the Great Xing'an Mountains.
Second, we assumed that forest management planning and timber harvest methods remained unchanged. The harvest practices were strictly carried out according to forest management planning in the LANDIS PRO model. However, timber harvesting without permission was not simulated in our study
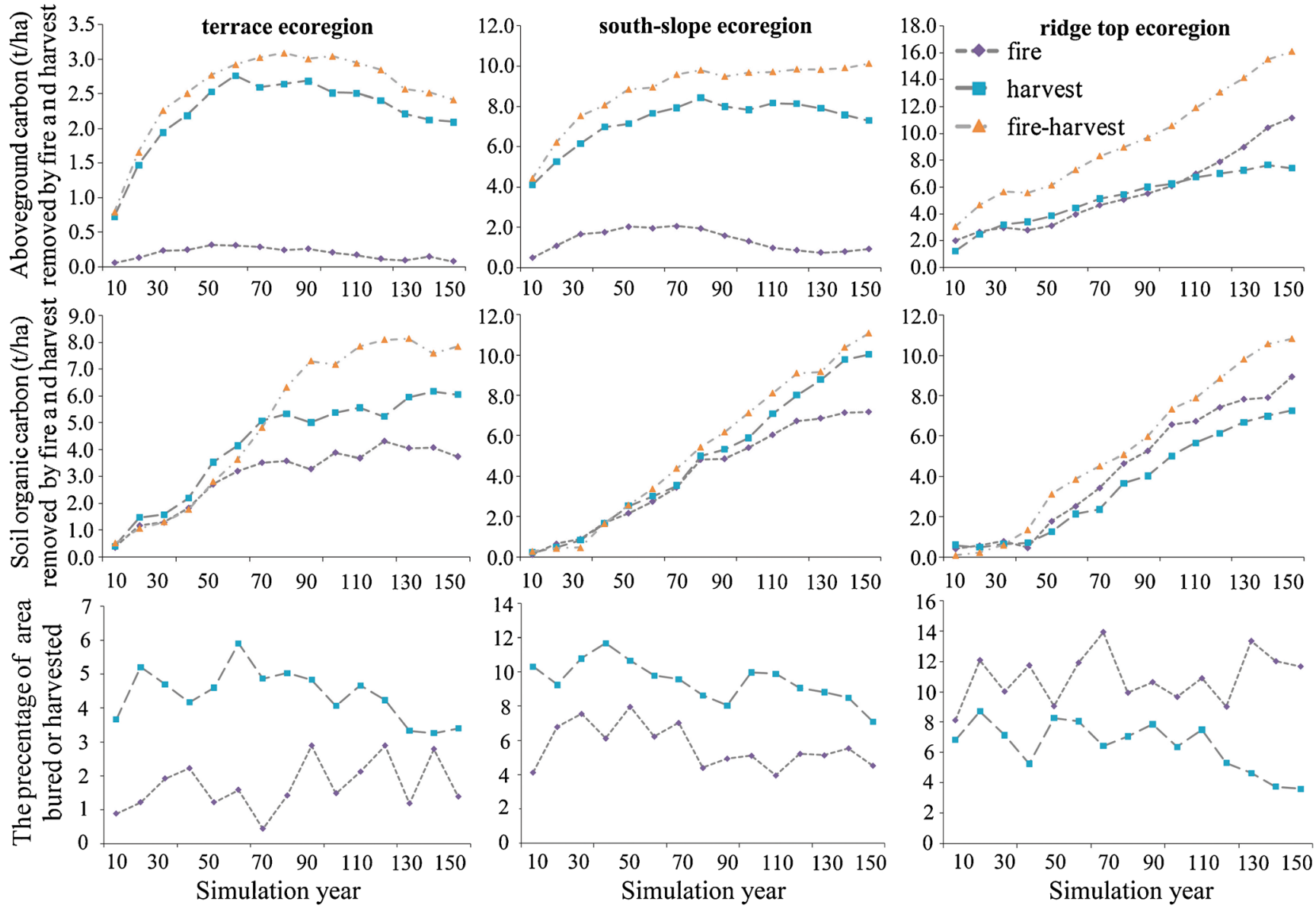

Fig. 8 Effects of fire and harvest on aboveground carbon and soil organic carbon in three example ecoregions. The top panels show aboveground carbon removed by fire or harvest. The top panels show aboveground carbon removed by fire or harvest. The middle panels show soil organic carbon that was removed by fire or harvest. The bottom panels show the percentage of ecoregion area that burned or was harvested 
but is an observed activity. Our study may underestimate the effects of harvest on boreal forest carbon stocks because we have not considered illegal logging activities. Besides, we did not track the carbon stocks of forest products, so we might overestimate the effects of harvest. Third, species life history attributes and the relationships between species establishment probability and environmental factors (topography, elevation, and climate) were constant, which in reality likely vary across different environmental conditions (Levesque et al. 2013). These factors may alter the effects of fire and harvest and their spatial interactions on boreal forest carbon stocks. Fourth, we did not include carbon stocks of forest understory in our simulations. This was because the understory accounts for less than $3 \%$ of total aboveground carbon in our study area. A previous field study showed that fire has no significant effects on shrub and herb carbon stocks in the boreal forests of the Great Xing'an Mountains (Yang 2015).

The initial forest conditions in 2000, from a legacy of decades of timber harvest, fire, and forest succession, could have a great effect on subsequent simulation results. Two major sources of uncertainties of forest inventory data included (1) decade-long time span (1990-2000) of the inventory data and (2) misregistration of inventory data to forest stands. Our underlining hypothesis is that the 9-year time difference in forest age and stand-level information mismatch does not affect the long-term simulation results. First, our simulations were conducted at a 10-year time step in which for example, a 40-year-old stand and a 49-year-old stand were treated as 40-year-old stand. Since trees are long lived with average longevity ranging from 150 to 300 years, the 9 -year age difference in the inventory data should not affect our overall results. Second, Xu et al. (2004) found that the effects of cell-level uncertainties had little effect on long-term LANDIS model simulation results. Therefore, we believe that stand-level information mismatch in our study should not alter our overall results and conclusion.

The effects of fire and harvest on soil physical and chemical processes were not taken into consideration in this study. Previous studies showed that root decomposition after harvesting and charcoal sequestration after fire play an important role in soil organic carbon dynamics (Johnson et al. 1991; Wardle et al. 2008). In boreal forests, fire converts a fraction of the burning vegetation to charcoal carbon. Charcoal carbon is slow to decompose, and the formation of this reserve therefore creates a long-term soil carbon sink (Czimczik et al. 2005). However, the rate of charcoal sequestration and root decomposition after disturbances is not well understood (Fahey and Arthur 1994; Ohlson et al. 2009). Thus, the effects of root decomposition and charcoal sequestration on soil carbon stocks were not taken into consideration in this study. Although these assumptions and limitations created uncertainly in our simulation results, the results from our study still can be used to identify general trends in the response of boreal forest carbon stocks to fire, harvest, and their spatial interactions under current climate conditions, disturbance regimes, and forest management practices.

\section{Conclusions}

In this study, we found that boreal forest carbon stocks are significantly altered by fire, harvest, and their spatial interactions. Our simulation results suggested that the long-term effects of fire and harvest on boreal forest carbon stocks are greater than those short-term effects at the landscape level. The relative importance of fire and harvest on boreal forest carbon stocks was dependent on the intensity of these disturbances. Because timber harvesting reduces the amount of carbon loss to fires, the combined effects of fire and harvest on boreal forests are less than the sum of the separate effects of fire and harvest. Spatial variation in the effects of fire and harvest on boreal forest carbon stocks is caused by diverse disturbance regimes among different ecoregions. These results have important implications for forest managers to design and implement sustainable forest fire and harvest strategies to maintain carbon stocks of boreal forests.

Acknowledgments The authors thank the workgroup from the Huzhong Forestry Bureau for field investigations. Any use of trade, product, or firm names is for descriptive purposes only and does not imply endorsement by the U.S. Government.

Funding This work was supported by the National Key Research and Development Program of China (2016YFA0600804), the USGS-MOST project, the National Biologic Carbon Sequestration Assessment Program under the U.S. Geological Survey Climate and Land Use Mission Area, and the Chinese National Science Foundational Project (Nos. 41371199, 31570462, and 31570461).

\section{Compliance with ethical standards}

Conflict of interest The authors declare that they have no conflict of interest.

\section{References}

Alexandrov GA (2007) Carbon stock growth in a forest stand: the power of age. Carbon Balance Manag 2:4. https://doi.org/10.1186/17500680-2-4

Anderson-Teixeira KJ, Miller AD, Mohan JE, Hudiburg TW, Duval BD, DeLucia EH (2013) Altered dynamics of forest recovery under a changing climate. Glob Chang Biol 19:2001-2021. https://doi.org/ 10.1111/gcb.12194

Barker JS, Simard SW, Jones MD (2014) Clearcutting and high severity wildfire have comparable effects on growth of direct-seeded interior Douglas-fir. For Ecol Manag 331:188-195. https://doi.org/10.1016/ j.foreco.2014.08.004

Belmaker J, Jetz W (2011) Cross-scale variation in species richnessenvironment associations. Glob Ecol Biogeogr 20:464-474. https://doi.org/10.1111/j.1466-8238.2010.00615.x 
Bergeron Y, Gauthier S, Kafka V, Lefort P, Lesieur D (2001) Natural fire frequency for the eastern Canadian boreal forest: consequences for sustainable forestry. Can J For Res 31:384-391

Bhatti JS, Apps MJ, Jiang H (2002) Influence of nutrients, disturbances and site conditions on carbon stocks along a boreal forest transect in central Canada. Plant Soil 242:1-14. https://doi.org/10.1023/a: 1019670619316

Boby LA, Schuur EAG, Mack MC, Verbyla D, Johnstone JF (2010) Quantifying fire severity, carbon, and nitrogen emissions in Alaska's boreal forest. Ecol Appl 20:1633-1647. https://doi.org/ 10.1890/08-2295.1

Bose AK, Harvey BD, Brais S, Beaudet M, Leduc A (2013) Constraints to partial cutting in the boreal forest of Canada in the context of natural disturbance-based management: a review. Forestry 87:11-28

Bury RB (2004) Wildfire, fuel reduction, and herpetofaunas across diverse landscape mosaics in northwestern forests. Conserv Biol 18: 968-975

Cai WH, Yang J, Liu Z, Hu YM, Liu SJ, Jing GZ, Zhao ZF (2012) Controls of post-fire tree recruitment in Great Xing'an Mountains in Heilongjiang Province. Acta Ecol Sin 32:3303-3312. https://doi. org/10.5846/stxb201105030574

Cai WH, Yang J, Liu Z, Hu Y, Weisberg PJ (2013) Post-fire tree recruitment of a boreal larch forest in northeast China. For Ecol Manag 307:20-29

Carlson CH, Dobrowski SZ, Safford HD (2012) Variation in tree mortality and regeneration affect forest carbon recovery following fuel treatments and wildfire in the Lake Tahoe Basin, California, USA. Carbon Balance Manag 7:1-17. https://doi.org/10.1186/1750-06807-7

Carvalhais N, Forkel M, Khomik M, Bellarby J, Jung M, Migliavacca M, Mu M, Saatchi S, Santoro M, Thurner M, Weber U, Ahrens B, Beer C, Cescatti A, Randerson JT, Reichstein M (2014) Global covariation of carbon turnover times with climate in terrestrial ecosystems. Nature 514:213-217

Chen HYH, Shrestha BM (2012) Stand age, fire and clearcutting affect soil organic carbon and aggregation of mineral soils in boreal forests. Soil Biol Biochem 50:149-157. https://doi.org/10.1016/j. soilbio.2012.03.014

Chen JM, Ju W, Cihlar J, Price D, Liu J, Chen W, Pan J, Black A, Barr A (2003) Spatial distribution of carbon sources and sinks in Canada's forests. Tellus B 55:622-641

Chen W, Moriya K, Sakai T, Koyama L, Cao C (2014) Post-fire forest regeneration under different restoration treatments in the Greater Hinggan Mountain area of China. Ecol Eng 70:304-311

Chen HW, Hu YM, Chang Y, Bu RC, Li YH, Liu M (2015) Changes of forest fire regime and landscape pattern under different harvesting modes in a boreal forest of northeast China. J Arid Land 7:841-851. https://doi.org/10.1007/s40333-015-0015-2

Cheng CH, Chen YS, Huang YH, Chiou CR, Lin CC, Menyailo OV (2013) Effects of repeated fires on ecosystem $\mathrm{C}$ and N stocks along a fire induced forest/grassland gradient. J Geophys Res Biogeosci 118:215-225. https://doi.org/10.1002/jgrg.20019

Chertov O, Bhatti JS, Komarov A, Mikhailov A, Bykhovets S (2009) Influence of climate change, fire and harvest on the carbon dynamics of black spruce in central Canada. For Ecol Manag 257:941-950. https://doi.org/10.1016/j.foreco.2008.10.038

Clarke N, Gundersen P, Jönsson-Belyazid U, Kjønaas OJ, Persson T, Sigurdsson BD, Stupak I, Vesterdal L (2015) Influence of different tree-harvesting intensities on forest soil carbon stocks in boreal and northern temperate forest ecosystems. For Ecol Manag 351:9-19. https://doi.org/10.1016/j.foreco.2015.04.034

Czimczik CI, Mwi S, Schulze ED (2005) Effects of increasing fire frequency on black carbon and organic matter in Podzols of Siberian Scots pine forests. Eur J Soil Sci 56:417-428

Dean C, Roxburgh S, Mackey BG (2004) Forecasting landscape-level carbon sequestration using gridded, spatially adjusted tree growth.
For Ecol Manag 194:109-129. https://doi.org/10.1016/j.foreco. 2004.02.013

Dijak WD, Hanberry BB, Fraser JS, He HS, Wang WJ, Thompson FR (2016) Revision and application of the LINKAGES model to simulate forest growth in central hardwood landscapes in response to climate change. Landsc Ecol 32:1-20

Fahey TJ, Arthur MA (1994) Further studies of root decomposition following harvest of a northern hardwoods forest. For Sci 40:618-629

Flannigan MD, Logan KA, Amiro BD, Skinner WR, Stocks B (2005) Future area burned in Canada. Clim Chang 72:1-16

Fraser JS, He HS, Shifley SR, Wang WJ, Thompson FR (2013) Simulating stand-level harvest prescriptions across landscapes: LANDIS PRO harvest module design. Can J For Res 43:972-978. https://doi.org/10.1139/cjfr-2013-0190

$\mathrm{Fu} \mathrm{H}$, Wei Y, Jingjing C (2013) Forest carbon storage and it's dynamics in the Great Xing'an Mountains Inner Mongolia. J Arid Land Resour Environ 27:166-170

Goetz SJ, Bond-Lamberty B, Law BE, Hicke JA, Huang C, Houghton RA, McNulty S, O'Halloran T, Harmon M, Meddens AJH, Pfeifer EM, Mildrexler D, Kasischke ES (2012) Observations and assessment of forest carbon dynamics following disturbance in North America. J Geophys Res Biogeosci 117. https://doi.org/10.1029/ 2011jg001733

Gough CM, Vogel CS, Harrold KH, George K, Curtis PS (2007) The legacy of harvest and fire on ecosystem carbon storage in a north temperate forest. Glob Chang Biol 13:1935-1949

Govind A, Chen JM, Bernier P, Margolis H, Guindon L, Beaudoin A (2011) Spatially distributed modeling of the long-term carbon balance of a boreal landscape. Ecol Model 222:2780-2795. https://doi. org/10.1016/j.ecolmodel.2011.04.007

Gromping U (2006) Relative importance for linear regression in R: the package relaimpo. J Stat Softw 17:925-933

Gustafson EJ, Shvidenko AZ, Sturtevant BR, Scheller RM (2010) Predicting global change effects on forest biomass and composition in south-central Siberia. Ecol Appl 20:700-715. https://doi.org/10. 1890/08-1693.1

Hazlett PW, Gordon AM, Voroney RP, Sibley PK (2007) Impact of harvesting and logging slash on nitrogen and carbon dynamics in soils from upland spruce forests in northeastern Ontario. Soil Biol Biochem 39:43-57. https://doi.org/10.1016/j.soilbio.2006.06.008

He HS, Mladenoff DJ (1999) Spatially explicit and stochastic simulation of forest-landscape fire disturbance and succession. Ecology 80:8199

He HS, Hao ZQ, Mladenoff DJ, Shao GF, Hu YM, Chang Y (2005) Simulating forest ecosystem response to climate warming incorporating spatial effects in north-eastern China. J Biogeogr 32:20432056. https://doi.org/10.1111/j.1365-2699.2005.01353.x

He HS, Yang J, Shifley SR, Thompson FR (2011) Challenges of forest landscape modeling - simulating large landscapes and validating results. Landsc Urban Plan 100:400-402

He HS, Gustafson EJ, Lischke H (2017) Modeling forest landscapes in a changing climate: theory and application. Landsc Ecol 32:1-7

Hu H, Wei S, Sun L (2012) Estimation of carbon emissions due to forest fire in Daxing'an Mountains from 1965 to 2010. Chinese J Plant Ecol 36:629-644

Hu XY, Zhu JX, Wang CK, Zheng TL, Wu QQ, Yao H, Fang JY (2016) Impacts of fire severity and post-fire reforestation on carbon pools in boreal larch forests in northeast China. J Plant Ecol 9:1-9. https:// doi.org/10.1093/jpe/rtv036

Huang C, He HS, Hawbaker TJ, Liang Y, Gong P, Wu Z, Zhu Z (2017) A coupled modeling framework for predicting ecosystem carbon dynamics in boreal forests. Environ Model Softw 93:332-343

Jiang H, Apps MJ, Peng CH, Zhang YL, Liu JX (2002) Modelling the influence of harvesting on Chinese boreal forest carbon dynamics. For Ecol Manag 169:65-82. https://doi.org/10.1016/s0378-1127 (02)00299-2 
Johnson DW, Curtis PS (2001) Effects of forest management on soil C and N storage: meta analysis. For Ecol Manag 140:227-238

Johnson CE, Johnson AH, Huntington TG, Siccama TG (1991) Wholetree clear-cutting effects on soil horizons and organic-matter pools. Soil Sci Soc Am J 55:497-502. https://doi.org/10.2136/sssaj1991. $03615995005500020034 \mathrm{x}$

Johnstone JF, Chapin FS (2006) Fire interval effects on successional trajectory in boreal forests of northwest Canada. Ecosystems 9: 268-277. https://doi.org/10.1007/s10021-005-0061-2

Kashian DM, Romme WH, Tinker DB, Turner MG, Ryan MG (2006) Carbon storage on landscapes with stand-replacing fires. Bioscience 56:598-606

Kasischke ES, Stocks BJ (2012) Fire, climate change, and carbon cycling in the boreal forest, vol 138. Springer, New York

Kasischke ES, Amiro BD, Barger NN, French NHF, Goetz SJ, Grosse G, Harmon ME, Hicke JA, Liu S, Masek JG (2013) Impacts of disturbance on the terrestrial carbon budget of North America. J Geophys Res Biogeosci 118:303-316. https://doi.org/10.1002/jgrg.20027

Kiefer MT, Heilman WE, Zhong S, Charney JJ, Bian X (2016) A study of the influence of forest gaps on fire-atmosphere interactions. Atmos Chem Phys 16:8499-8509

Kurz WA, Stinson G, Rampley GJ, Dymond CC, Neilson ET (2008) Risk of natural disturbances makes future contribution of Canada's forests to the global carbon cycle highly uncertain. Proc Natl Acad Sci 105:1551-1555

Levesque M, Saurer M, Siegwolf R, Eilmann B, Brang P, Bugmann H, Rigling A (2013) Drought response of five conifer species under contrasting water availability suggests high vulnerability of Norway spruce and European larch. Glob Chang Biol 19:3184 3199. https://doi.org/10.1111/gcb.12268

Li X, He HS, Wu Z, Liang Y, Schneiderman JE (2013) Comparing effects of climate warming, fire, and timber harvesting on a boreal forest landscape in northeastern China. PLoS One 8:e59747. https://doi. org/10.1371/journal.pone.0059747

Liang Y, He HS, Yang J, Wu ZW (2012) Coupling ecosystem and landscape models to study the effects of plot number and location on prediction of forest landscape change. Landsc Ecol 27:1031-1044. https://doi.org/10.1007/s10980-012-9759-7

Liu Z, Yang J, Chang Y, Weisberg PJ, He HS (2012) Spatial patterns and drivers of fire occurrence and its future trend under climate change in a boreal forest of northeast China. Glob Chang Biol 18:20412056. https://doi.org/10.1111/j.1365-2486.2012.02649.x

Luo X, He HS, Liang Y, Wang WJ, Wu Z, Fraser JS (2014) Spatial simulation of the effect of fire and harvest on aboveground tree biomass in boreal forests of northeast China. Landsc Ecol 29: 1187-1200. https://doi.org/10.1007/s10980-014-0051-x

Luo X, He HS, Liang Y, Wu ZW (2015) Evaluating simulated effects of succession, fire, and harvest for LANDIS PRO forest landscape model. Ecol Model 297:1-10. https://doi.org/10.1016/j.ecolmodel. 2014.10.040

Lutz DA, Shugart HH, Ershov DV, Shuman JK, Isaev AS (2013) Boreal forest sensitivity to increased temperatures at multiple successional stages. Ann For Sci 70:299-308. https://doi.org/10.1007/s13595012-0258-4

Moroni MT, Shaw CH, Otahal P (2010) Forest carbon stocks in Newfoundland boreal forests of harvest and natural disturbance origin I: field study. Can J For Res 40:2135-2145. https://doi.org/10. 1139/x10-154

Nalder IA, Wein RW (1999) Long-term forest floor carbon dynamics after fire in upland boreal forests of western Canada. Glob Biogeochem Cycles 13:951-968. https://doi.org/10.1029/ $1999 \mathrm{gb} 900056$

O’Donnell JA, Harden JW, McGuire AD, Kanevskiy MZ, Jorgenson MT, $\mathrm{Xu}$ X (2011) The effect of fire and permafrost interactions on soil carbon accumulation in an upland black spruce ecosystem of interior
Alaska: implications for post-thaw carbon loss. Glob Chang Biol 17: 1461-1474. https://doi.org/10.1111/j.1365-2486.2010.02358.x

Ohlson M, Dahlberg B, Økland T, Brown KJ, Halvorsen R (2009) The charcoal carbon pool in boreal forest soils. Nat Geosci 2:692-695

Pan YD, Birdsey RA, JY Fang RH, Kauppi PE, Kurz WA, OL Phillips AS, Lewis SL, Canadell JG, Ciais P, Jackson RB, Pacala SW, McGuire AD, Piao SL, Rautiainen A, Sitch S, Hayes D (2011) A large and persistent carbon sink in the world's forests. Science 333: 988-993. https://doi.org/10.1126/science.1201609

Piirainen S, Finér L, Starr M (2015) Changes in forest floor and mineral soil carbon and nitrogen stocks in a boreal forest after clear-cutting and mechanical site preparation. Eur J Soil Sci 66:735-743. https:// doi.org/10.1111/ejss. 12264

Post WM, Pastor J (1996) Linkages - an individual-based forest ecosystem model. Clim Chang 34:253-261

R Core Team (2015) R: a language and environment for statistical computing. R Foundation for Statistical Computing, Vienna

Running SW (2008) Ecosystem disturbance, carbon, and climate. Science 321:652-653

Scheller RM, Kretchun AM, Van Tuyl S, Clark KL, Lucash MS, Hom J (2012) Divergent carbon dynamics under climate change in forests with diverse soils, tree species, and land use histories. Ecosphere 3: 1-16. https://doi.org/10.1890/es12-00241.1

Serrano-Ortiz P, Marañón-Jiménez S, Reverter BR, Sánchez-Cañete EP, Castro J, Zamora R, Kowalski AS (2011) Post-fire salvage logging reduces carbon sequestration in Mediterranean coniferous forest. For Ecol Manag 262:2287-2296. https://doi.org/10.1016/j.foreco. 2011.08.023

Shanin VN, Komarov AS, Mikhailov AV, Bykhovets SS (2011) Modelling carbon and nitrogen dynamics in forest ecosystems of Central Russia under different climate change scenarios and forest management regimes. Ecol Model 222:2262-2275

Shifley SR, Iii FRT, Dijak WD, Larson MA, Millspaugh JJ (2006) Simulated effects of forest management alternatives on landscape structure and habitat suitability in the Midwestern United States. For Ecol Manag 229:361-377

Shrestha BM, Chen HYH (2010) Effects of stand age, wildfire and clearcut harvesting on forest floor in boreal mixedwood forests. Plant Soil 336:267-277. https://doi.org/10.1007/s11104-010-04752

Steenberg JWN, Duinker PN, Bush PG (2012) Modelling the effects of climate change and timber harvest on the forests of central Nova Scotia, Canada. Ann For Sci 70:61-73. https://doi.org/10.1007/ s13595-012-0235-y

Thornley JHM, Cannell MGR (2004) Long-term effects of fire frequency on carbon storage and productivity of boreal forests: a modeling study. Tree Physiol 24:765-773. https://doi.org/10.1093/treephys/ 24.7.765

Wang WJ, He HS, Fraser JS, Thompson FR, Shifley SR, Spetich MA (2014a) LANDIS PRO: a landscape model that predicts forest composition and structure changes at regional scales. Ecography 37: 225-229. https://doi.org/10.1111/j.1600-0587.2013.00495.x

Wang WJ, He HS, Spetich MA, Shifley SR, Thompson FR, Dijak WD, Wang Q (2014b) A framework for evaluating forest landscape model predictions using empirical data and knowledge. Environ Model Softw 62:230-239. https://doi.org/10.1016/j.envsoft.2014.09.003

Wang WJ, He HS, Thompson FR, Fraser JS, Dijak WD (2016) Landscape- and regional-scale shifts in forest composition under climate change in the central hardwood region of the United States. Landsc Ecol 31:149-163. https://doi.org/10.1007/s10980015-0294-1

Wardle DA, Nilsson M-C, Zackrisson O (2008) Fire-derived charcoal causes loss of forest humus. Science 320:629-629. https://doi.org/ $10.1126 /$ science. 1154960

Wirth C, Schulze ED, Schulze W, von Stünzner-Karbe D, Ziegler W, Miljukova IM, Sogatchev A, Varlagin AB, Panvyorov M, 
Grigoriev S, Kusnetzova W, Siry M, Hardes G, Zimmermann R, Vygodskaya NN (1999) Above-ground biomass and structure of pristine Siberian Scots pine forests as controlled by competition and fire. Oecologia 121:66-80. https://doi.org/10.1007/ s004420050908

Wu Z, He HS, Yang J, Liu Z, Liang Y (2014) Relative effects of climatic and local factors on fire occurrence in boreal forest landscapes of northeastern China. Sci Total Environ 493:472-480

Wu Z, He HS, Yang J, Liang Y (2015) Defining fire environment zones in the boreal forests of northeastern China. Sci Total Environ 518-519: 106-116

Wullschleger SD, Gunderson CA, Tharp ML, West DC, Post WM (2003) Simulated patterns of forest succession and productivity as a consequence of altered precipitation. In: Hanson PJ, Wullschleger SD (eds) North American temperate deciduous forest responses to changing precipitation regimes. Springer, New York, pp 433-446

Xu C, He HS, Hu Y, Chang Y, Larsen DR, Li X, Bu R (2004) Assessing the effect of cell-level uncertainty on a forest landscape model simulation in northeastern China. Ecol Model 180:57-72
Xu H, Dong H, Di G, Liu B (2006) Natural regeneration of main tree species in deforested lands in Daxing'an Mountains. J Northeast For Univ 34:18-21. https://doi.org/10.13759/j.cnki.dlxb.2006.01.007

Yang D (2015) Influence of fire disturbance on aboveground carbon storage in forest region of Great Xing'an Mountains Northeast China, University of Chinese Academy of Sciences, Beijing, pp 31-38

Yang J, He HS, Gustafson EJ (2004) A hierarchical fire frequency model to simulate temporal patterns of fire regimes in LANDIS. Ecol Model 180:119-133

Yang J, He HS, Shifley SR (2008) Spatial controls of occurrence and spread of wildfires in the Missouri Ozark Highlands. Ecol Appl 18:1212-1225

Zha T, Barr AG, Black T, McCaughey JH, Bhatti J, Hawthorne I, Krishnan P, Kidston J, Saigusa N, Shashkov A (2009) Carbon sequestration in boreal jack pine stands following harvesting. Glob Chang Biol 15:1475-1487

Zhang H, Hu Y, Duan C, Li Y, Zhang C (2009) Study on the forest resource change and its influence on the economic and social activities in the Great Xing'an Mountains. J Anhui Agric Sci 37:15001-15005 